\title{
MONITORING OF VEGETATION CHANGE BY USING RS AND GIS TECHNIQUES IN MITROVICA, KOSOVO
}

\author{
Edon Maliqii, ${ }^{1,2}$ and Petar Penev ${ }^{2}$ \\ 1 “Geo - SEE Institute” branch office in Kosovo. Pristina, Kosovo. \\ ${ }^{2}$ University of Architecture, Civil Engineering and Geodesy. Sofia, Bulgaria. \\ Email: edon.maliqi@gmail.com ; Tel: 0038344446128
}

Keywords: Vegetation monitoring, Satellite image, NDVI, Time series maps, DEM, Land cover. Abstract: Monitoring environment changes has become a necessity as a result of current
environment deteriorating due to human activities like mining activities. In most
developing countries like Kosovo (Mitrovica), acquiring information concerning the
current condition and the dynamic changes of the environment for a rapid monitoring is
not easy. The present study provides The Normalized Difference vegetation Index (NDVI)
of the study area, Mitrovica. The main aim of the study is to monitor and evaluate changes
in vegetation over the years, using NDVI time series outputs. As well as this technique of
monitoring vegetation will be used to evaluate drying vegetation as e result of the mining
tailings in this area, exactly because of the presence of the heavy metals that come by
industrial activities in this region.
The NDVI technique involves the use of remote sensed data in different time series
extracted from Landsat 5 and Landsat 8 . The Landsat satellite images give us reliable
information for monitoring vegetation change according in NDVI time series. According
to the present study, the NDVI data generated gives us valuable informations about
vegetation. However, the study demonstrated that in Mitrovica was changed the vegetation
over the years as result of human mining activities and climate change as well. The NDVI
technique can be employed for monitoring vegetation cover and it's values range from - 1
to 1 . The present study shows monitoring vegetation changes for 2000 , 2010 and 2018 .
The NDVI time series Mitrovica maps computed in the study, range from -0.30 to 0.26 in
2000, from - 0.09 to 0.47 in 2010 and -0.14 to 0.60 in 2018 . This technique can be applied
in different areas in the country and will be effective tool for environmental monitoring
and evaluating vegetation change and vegetation monitoring as well.
Furthermore, the study will answer to the many questions for vegetation change in
Mitrovica and its change ratio.

\section{INTRODUCTION}

Monitoring vegetation changes is important in agriculture and economy of state in national and international levels. Accurate and timely information for vegetation changes is crucial for policy 
makers and investitors. Vegetation indices are used for global monitoring of vegetation conditions and in products displaying land cover and land cover changes (Slik, 2016).

The usage of Normalized Difference Vegetation Index study is numerous. But it is frequently used for monitoring drought, monitor and predict the agricultural production, vegetation monitoring from year-to-year and predicting natural hazardous (Arulbalaji and Gurugnanam, 2014).

Vegetation indices (VIs), based on satellite observations, are mathematical transformations of reflectance measurements in different spectral bands, especially the visible (usually red) and nearinfrared bands, that are widely used to obtain information about land surface characteristics (Jackson and Huete, 1991). Over the years, a great number of VIs of varying complexity have been proposed, each with advantages and limitations (Bannari et al.,1995). The most commonly used VI is the Normalized Difference Vegetation Index (Rouse et al., 1973). Different proportions between vegetation cover and background soil may affect the relationship between NDVI and vegetation attributes in sparsely vegetated areas such as drylands (Huete and Jackson, 1988).

Remote Sensing techniques has become an important tool in environmental studies because it is able to give an objective, repeatable and cost effective information over large areas and can be empirically be referred to field data collected using traditional methods (Amiri and Tabatabaie, 2009). Commonly applied Remote Sensing technique in environmental monitoring is vegetation monitoring and evaluation through vegetation indices which integrate reflectance measurements from the bands of the sensor ( Bannari et al, 1995; Thiam and Eastman, 2001). These vegetation indices are acquired from the use of satellite imagery from various sensors.

The influence of mining tailings in the Mitrovica affect air, water, land and the entire environment and biodiversity. But this study aims to investigate changes in vegetation as a result of industrial acitivities and mining tailings located there as well. There is a big surface covered by vegetation and the study is going to analyse vegetation changes over the years respectively from 2000 to 2018. The output of the study will be NDVI time series maps of 2000, 2010 and 2018. The initial doubt is that vegetation of the area of this study has changed over the years but it is unmistakable change by peoples. Thus the study is going do investigate and response to these doubts by using Remote Sensing and Geographic Information Systems techniques included within NDVI. The response of the study will be whether mining tailings has affected in drying vegetation or not ? Another response derived by the study will be numerical and graphical representations of the vegetation changes. The final product will be NDVI time series maps generated, its analysis and intepretations. The study will be finished comparing the NDVI categories with Land Cover and DEM data, in order to test and confirm the performed results of the study and their reliability.

The NDVI generated form satellite images as Landsat 5 and Landsat 8 data was suitable for monitoring vegetation changes and dynamics in Mitrovica.

\section{A BRIEF THEORITICAL BACKGROUND}

The Normalized Difference Vegetation Index (NDVI) is a graphical indicator that can be used to analyse remote sensing data, and is used to carry out remote sensing measurements of vegetation. In other words the sensor can detect if the target surface has live vegetation cover or not (Slik, 2016).

Slik (2012) in his thesis, pointed out that data products provided are the Normalized Difference Vegetation Index (NDVI), Red - band, Near infrared - band and cloud data when available. The composite values are based on data quality and the maximum NDVI for the compositing period. The NDVI is a ratio of the red and near infrared reflectance. It is useful for assessing the health and density of vegetation. The NDVI technique can be employed for monitoring vegetation cover and it's values range from -1 to 1 . NDVI values near 0 such as -0.1 to 0.1 indicate barren areas of rock, sand or snow. Higher values of 0.1 to 0.4 indicate sparse vegetation of grassland and shrubs. Dense 
vegetation like tropical rainforests or temperate forest is indicated by NDVI values approaching values of 1 (Weier and Herring, 2013). By using time-series of NDVI observations, one can examine the dynamics of the growing season and monitor vegetation change such as drought.

The NDVI is defined as the ratio of difference between the near infrared and red reflectance to their sum. The NDVI algorithm subtracts the red reflectance values from the near-infrared and divides it by the sum of near-infrared and red bands (Reddy and Reddy, 2013). The formula to detect the NDVI is stated as follows:

$$
\text { NDVI = (NIR - RED) / (NIR + RED) }
$$

Based on the abovementioned principles and rules, will be monitored/calculated the vegetation change (NDVI) in Mitrovica as main objective of this study.

\section{RESEARCH OBJECTIVES}

The objectives of the study are based mainly in the following questions:

Does vegetation in Mitrovica changes over the years?

What kind of land cover has Mitrovica according NDVI time series values?

Which is relation of the NDVI comparing with DEM and Land Cover?

The study is going to adress and response the above questions and its objectives have derived by these questions.

\section{STUDY AREA}

The Mitrovica is bounded in the north part of Republic of Kosova, only $25 \mathrm{~km}$ from the capital Pristina. The stuy area extends along to shores of the Iber and Sitnica rivers. It is located between

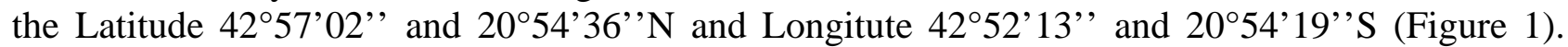
Total area covered $40 \mathrm{~km}^{2}$, the minimum elevation is $500 \mathrm{~m}$ and the maximum elevation is $1220 \mathrm{~m}$ whereas the most of the area is covered by highlands. According to the meteorological data for the Republic of Kosovo, the weather in subject region is continental with warm summers and cold snowy winters. The annual average precipitation is around $700 \mathrm{~mm}$ and moderate winds blowing predominantly from the northeast, average speed ranges $20 \mathrm{~m} / \mathrm{sec}-4.4 \mathrm{~m} / \mathrm{sec}$. In this part of the country, the winters are colder with medium temperatures above $-10^{\circ} \mathrm{C}$, but sometimes down to $26^{\circ} \mathrm{C}$. The summers are very hot with average temperatures of $20^{\circ} \mathrm{C}$, sometimes up to $37^{\circ} \mathrm{C}$.

The landscape consists of a system of hills and plateaus of flattened surfaces. The study area record two main seasons (wet and dry season). The wet season begins in March and lasts in September with a prolonged dry season between October and February. The geology of the study area is rather complicated and characterized by a variety of rocks spanning in age from Palaeozoic to Quaternary. The oldest terrains cropping out in the study area are mostly siliceous rocks, Palaeozoic in age, such as: metasandstones, quartzose schists, phyllites and quartzites, with minor strata of crystalline carbonate rocks.

The vegetation of the study is covered by water bodies, barren areas and rock surface, shrub and grass land and moderate forests. The study area lies close to main road that links Pristina and Mitrovica as well as within study area extends the railway (railway station). This part of the northern Kosovo constitutes one of the main industrial area in Kosovo as well as one of the most important mining district of Europe. In Mitrovica is located a huge mine named Trepça and could be concluded that there is a big industrial region. Because of this, there are two mining tailings (Kelmend and PIM), there is a high level presence of heavy metals in environment. Both of them covered an area of 60 hectares or $0.6 \mathrm{~km}^{2}$. 


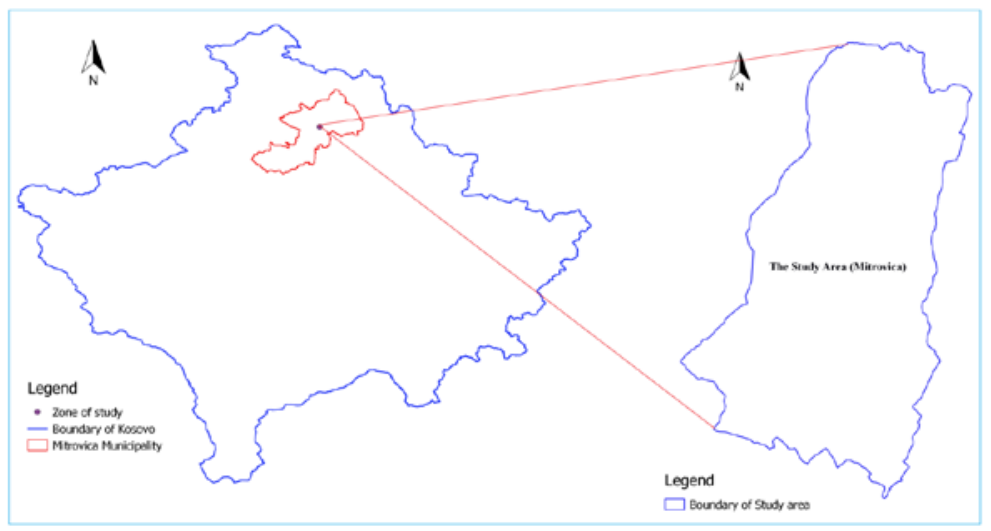

Figure 1. Map of the Study Area (Mitrovica).

\section{DATA AND METHODOLOGY}

\subsection{Source data and Data processing}

Numerous source data were obtained and used in the present study. The datasest images used in the study were obtained from Landsat 5 and Landsat 8 in different time series provided by U.S. Geological Survey. The spatial resolution of Landsat 5 and Landsat 8 used has been $30 \mathrm{~m}$. The Landsat 5 Thematic Mapper (TM) and Landsat 8 OLI/TIRS were downloaded from U.S. Geological Survey thorugh EarthExplorer (www.earthexplorer.usgs.gov). The images were acquired in May, June and July 2018. The Landsat 5 TM datasets of Mitrovica were acquired for 2000 and 2010, with 30m spatial resolution and it has 7 bands (band 1 - band 7), in order to generate the NDVI were used band 3 (Spectral Sensitivity: 0.63 - $0.69 \mu \mathrm{m}$ and Nominal Spectral Location: Red) and band 4 (Spectral Sensitivity: $0.76-0.90 \mu \mathrm{m}$ and Spectral Location: NIR) according to equation 1 . The Landsat 8 OLI/TIRS datasets were acquired for 2018 and have 30m spatial resolution and it has 11 bands (band 1 - band 11). To fulfill the aim of the present study were used band 4 (Spectral Sensitivity: 0.63 - 0.67 $\mu \mathrm{m}$ and Nominal Spectral Location: Red) and band 5 (Spectral Sensitivity: $0.85-0.88 \mu \mathrm{m}$ and Spectral Location: NIR). In the study were used as well the Digital Elevation Model (DEM) acquired from ALOS (Advanced Land Observation Satellite) with 20m spatial resolution, which wavelength region stands from 0.42 to $0.99 \mu \mathrm{m}$. The land cover map was provided by Copernicus Land Monitoring Service. The Land Cover datasets of 2012 were obtained from Copernicus site (www.land.copernicus.eu). As well as in the study were used the boundary of study area and boundary of mining tailings within the study which were in the vectoral format (shapefile) obtained from Kosovo Cadastral Agency and Ministry of Environmental and Sparial Planning in Kosovo. Based on the source data mentioned above were produced the NDVI time series maps of years: 2000, 2010 and 2018, which was use to monitor vegetation changes in Mitrovica. Due to various sources of input data, the obtained and collected data have been in different formats and reference systems. Thus, the first step as a precondition toward study developing were data harmonization process. The source data (satellite images) were proccessed in QGIS software version 3.0 and the output cartographic products have been in the KosovaRef01 coordinate system (Kosovo coordinate system), whose parameters are know already. As the final output of the study aims to produce the NDVI time series maps and they will be analysed and compared with DEM and Land Cover datastes, in order to monitor vegetation changes in Mitrovica. The cartographic products (NDVI time series maps) were developed as GeoTIFF file and the NDVI pattern will be classified as multicolor pattern that shown NDVI range values or NDVI classes. As well as the cartographic outputs (NDVI time series maps) have been compiled and prepared using the QGIS 
software tool and the analysis have been demonstrated supporting QGIS software options. The following figure (Figure 2), gives the workflow diagram and processing method used in the study.

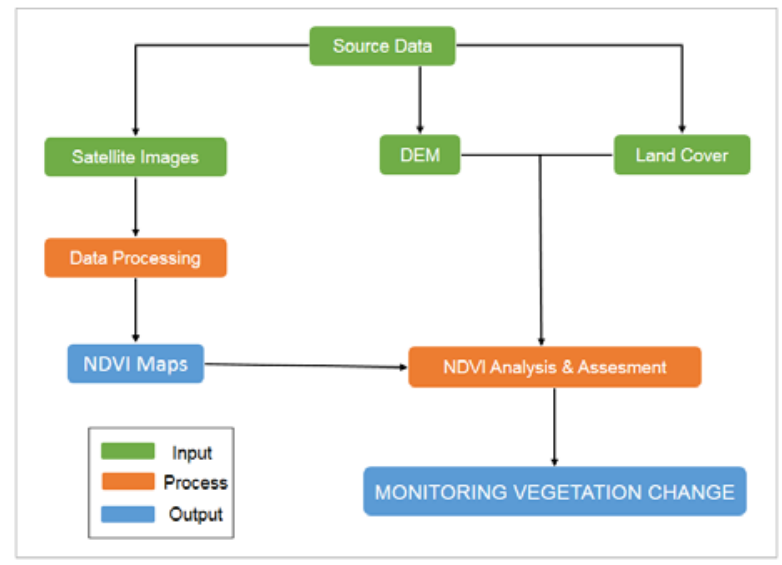

Figure 2. The Study workflow diagram

\subsection{The Normalized Difference Vegetation Index (NDVI)}

The nomeruos NDVI time series maps were calculated and produced using equation 1 . The NDVI values for the Mitrovica have been changed over the years. The NDVI values on year 2000 were in the ranges of -0.31 to 0.25 , where positive values show green vegetation cover and negative values show no vegetation cover. As well as the study shows that the NDVI values of 2010 were in the ranges of -0.09 to 0.47 . The NDVI values of 2018 have been in the ranges of -0.14 to 0.60 , where positive values show green vegetation like cropland and forests as well as negative values show non-vegetated features like water bodies, bare lands and clouds. The abovementioned values of 2000, 2010 and 2018 were compared with Land Cover categories (Corine Land Cover 2012) which will be treated in the next chapter. To monitor the vegetation change in Mitrovica 2000, 2010 and 2018, was used as zero series NDVI 2000 map and then was compared with NDVI 2010 map and NDVI 2018 map. The study as well has demonstrated the change ratio according time series. In order to detail vegetation variation in the study, the NDVI time series maps (2000, 2010 and 2018) were categorized into 5 NDVI categories as in the following table (Table 1 and Table 2). The categorizations of NDVI time series maps is done according to USGS NDVI values and Holben (1986). Thus, according USGS and Holben categorization, the present study covers the following vegetation indexes like barren, rock, water, shrubs, grasslands, dry bare soil, moderate vegetation, tropical and dense vegetation.

Table 1. NDVU values cover type according USGS.

\begin{tabular}{|lll|}
\hline No & Cover Type & NDVI Value \\
\hline $\mathbf{1}$ & Barren rock, sand, snow, water & 0.1 or Less \\
\hline $\mathbf{2}$ & Shrubs and Grasslands & 0.2 to 0.5 \\
\hline $\mathbf{3}$ & Dense Vegetation & 0.6 to 0.9 \\
\hline
\end{tabular}


Table 2. NDVI values for various cover type according Holben, 1986.

\begin{tabular}{|clc|}
\hline No & Cover Type & NDVI Value \\
\hline 1 & Dense Vegetation & 0.7 \\
\hline 2 & Dry Bare and soil & 0.025 \\
\hline 3 & Clouds & 0.002 \\
\hline 4 & Snow and Ice & -0.046 \\
\hline 5 & Water & -0.257 \\
\hline
\end{tabular}

In the study was compiled as well the NDVI map for 2000 of Mitrovica, as is shown in Figure 3. Then, in the study is determined cover type according NDVI values of USGS and Holben (1986). In the same methodology was acted for NDVI 2010 and NDVI 2018. Thus, in this way were compiled the NDVI time series maps of 2010 and 2018 and their cover type maps as well (Figure 4 and Figure 5).

Table 3. Mitrovica cover types according NDVI map 2000

\begin{tabular}{|clc|}
\hline No & Cover Type & NDVI Value \\
\hline 1 & Water Bodies & -0.06 to -0.30 \\
\hline 2 & Barren Area and Rock Surface & -0.30 to 0.12 \\
\hline 3 & Very Green Area & 0.12 to 0.26 \\
\hline
\end{tabular}

Figure 3. The NDVI values and cover type (2000).

Table 4. Mitrovica cover types according NDVI map 2010

\begin{tabular}{|llc|}
\hline No & Cover Type & NDVI Value \\
\hline 1 & Water Bodies & -0.09 to -0.35 \\
\hline 2 & Barren Area and Rock Surface & -0.35 to 0.05 \\
\hline 3 & Shrub and Grassland & 0.05 to 0.19 \\
\hline 4 & Moderate Green & 0.19 to 0.33 \\
\hline 5 & Tropical Forests & 0.33 to 0.47 \\
\hline 6 & Dense Vegetation & 0.47 to 0.70 \\
\hline
\end{tabular}



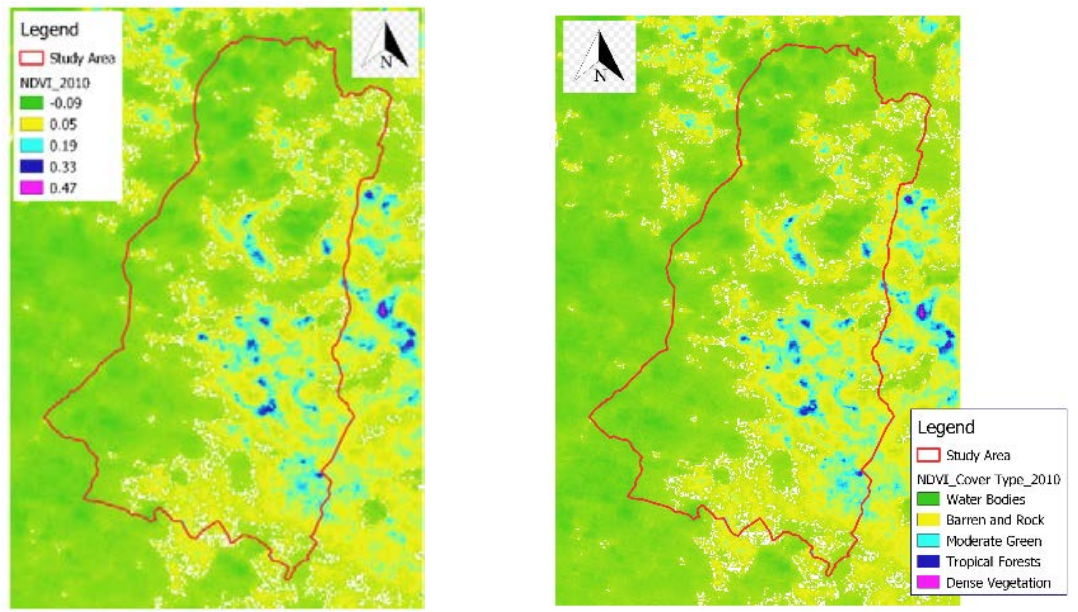

Figure 4. The NDVI values and cover type (2010).

Table 5. Mitrovica cover types according NDVI map 2018

\begin{tabular}{|llc|}
\hline No & Cover Type & NDVI Value \\
\hline 1 & Water Bodies & -0.14 to -0.35 \\
\hline 2 & Barren Area and Rock Surface & -0.35 to 0.05 \\
\hline 3 & Moderate and Very Green Area & 0.05 to 0.02 \\
\hline 4 & Tropical Forests & 0.02 to 0.42 \\
\hline 5 & Dense Vegetation & 0.42 to 0.70 \\
\hline
\end{tabular}
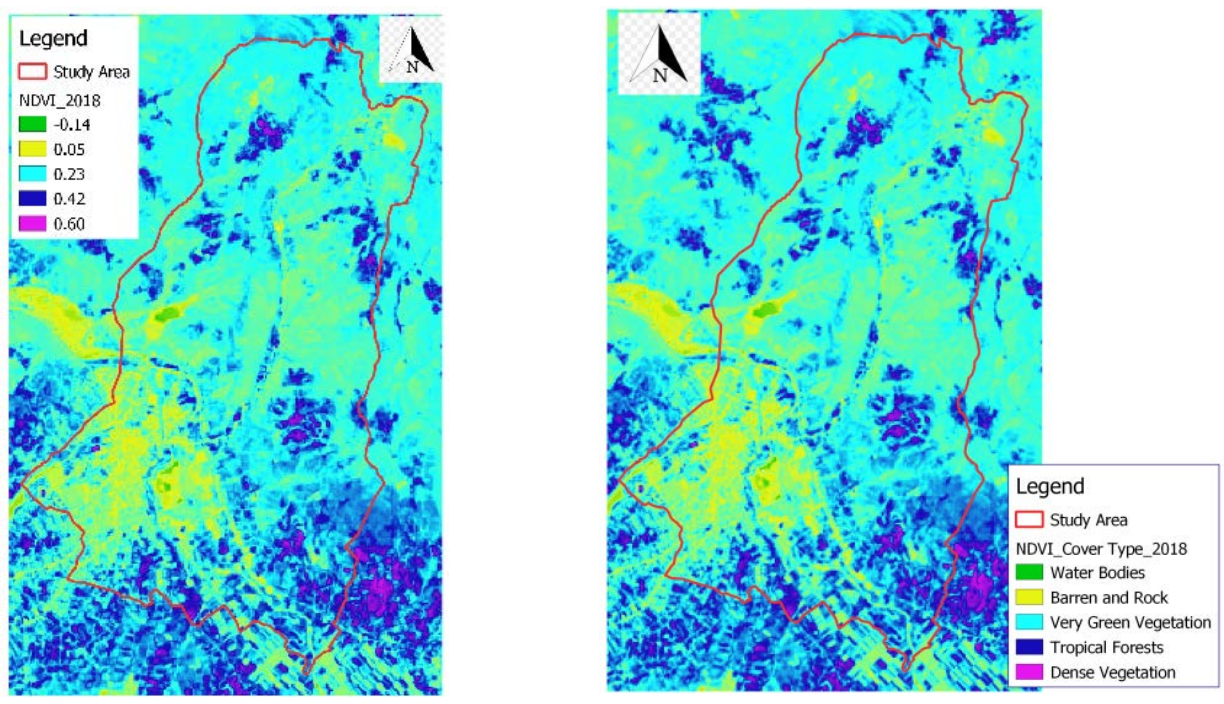

Figure 5. The NDVI values and cover type (2018).

In general, the study has shown that vegetation were changed over the years. The NDVI map of 2000 shows that the values of NDVI 2000 ranges from -0.06 to 0.26 . These values has demonstrated that the most of Mitrovica territory is cover by Water bodies, Barren area and Rock surfaces and there is just a little part of green vegetation. The NDVI map of 2010 shows that the values of NDVI 2010 ranges from -0.09 to 0.47 . According the NDVI 2010 values the territory of Mitrovica is coverd by Water bodies, Barren area and Rock surfaces, Shrub and Grasslands, Moderate Vegetation and a part of Dense Vegetation as is showed in NDVI map of 2010. As well as the NDVI map of 2018 shows that the values of NDVI 2018 ranges from -0.14 to 0.60 . These 
values has demonstrated and confirmed that Mitrovica territory in year 2018 is covered by Water bodies, Barren area and Rock surfaces, Moderate and Very green area, tropical forests and Dense vegetation. The monitoring procces of vegetation in Mitrovica shows that in 2000 there were a high level of drought. But in the last years the vegetation is being generated and is growing up as well. The NDVI map of 2010 has demonstrated that vegetation is more healthy than in 2000 as well as the NDVI map of 2018 has demonstrated that vegetation is more healthy than in 2010. The dry surface is running decreased in Mitrovica. The main cause of the vegetation change in Mitrovica remains industrial acitivity, esepcially until 2000. From 2000 was stopped the industrial acitivity in this region, therefore the vegetation is improving. Thus, mining tailings in Mitrovica should manage and monitor in order to have the minimum influence in environment in general and in vegetation in particular. Because the main source of vegetation drought remain mining tailings which were located in this region. Furthemore, the monitoring process of vegetation in Mitrovica in this time period, based on NDVI technique has demonstrated that Mitrovica vegetation is developing and improving. Therefore, this is a good news for the Mitrovica environment and its residents. Table 6 gives a few statistics of the NDVI values for the 2000, 2010 and 2018, generated by QGIS software tools. As well as here is shown a chart (Figure 6) of NDVI time series maps.

Table 6. Statistics of NDVI values 2000, 2010 and 2018 for Mitrovica .

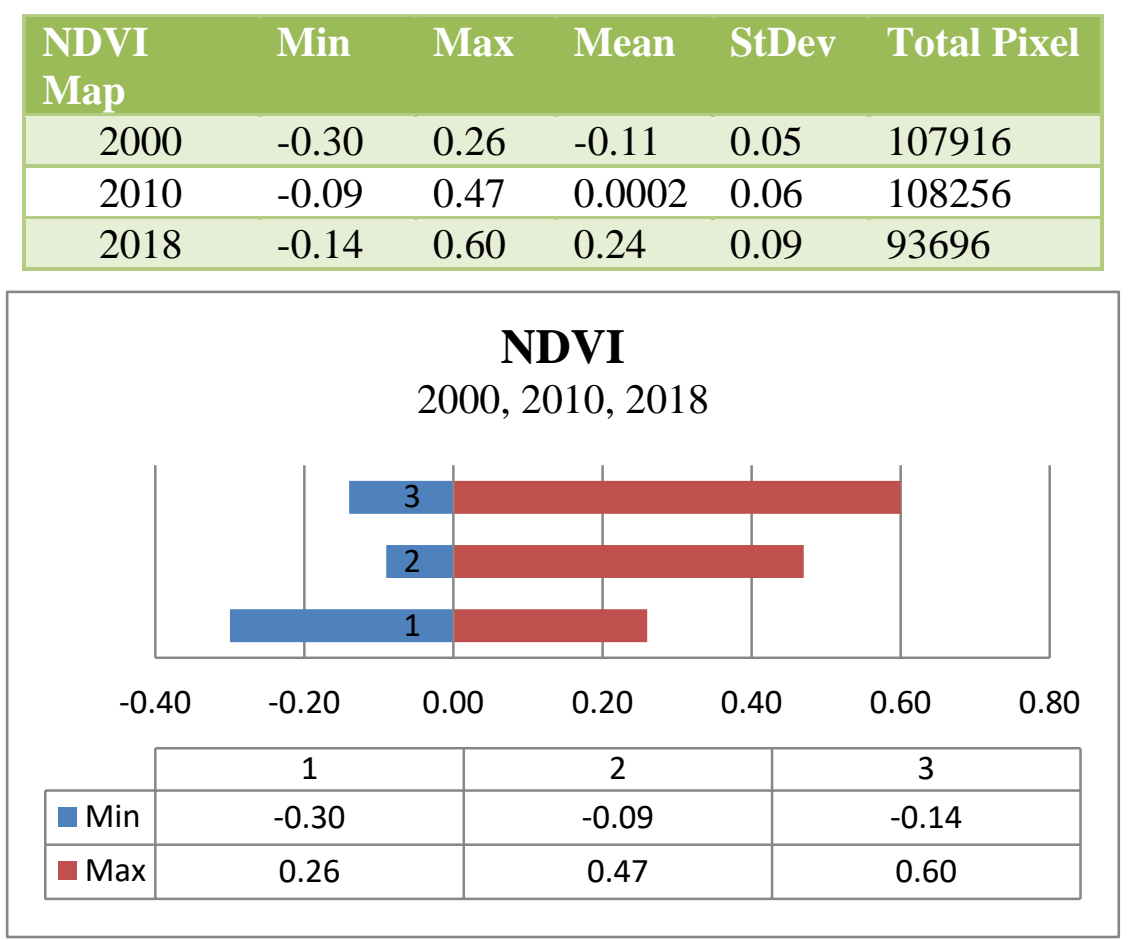

Figure 6. The chart of NDVI time series maps (2000, 2010 and 2018).

\subsection{Validity of NDVI time series}

In the present study, various data were obtained and have been compared and analyzed with performed NDVI time series maps (2000, 2010 and 2018). In order to evaluate performed NDVI maps, there have been an attempt to evaluate the NDVI time series accuracy and reliability. Thus, in the study were performed the comparison analysis between NDVI time series and others datasets such as DEM and Land Cover. To map the relations of NDVI time series maps compared with DEM and Land Cover were used DEM of $20 \mathrm{~m}$ spatial resolution acquired by ALOS. As well as was 
used Corine Land Cover 2012, acquired by Copernicus Land Monitoring Service. The next chapter will deal the comparative anylsis.

\section{COMPERATIVE ANALYSIS}

\subsection{NDVI \& LAND COVER}

The NDVI time series maps were compared with available Land Cover map downloaded by Copernicus Land Monitoring Service. The examined analysis aim to compare report between NDVI and Corine Land Cover 2012 categories. In all NDVI time series maps have been predicted correctly the vegetation cover for the most of Mitrovica surface, exception some situation where have been in the contrast to Land Cover map (CLC 2012). The detail analysis were performed in the next subchapters, in which were shown and compiled the vegetation change maps (NDVI time series maps) compared with CLC 2012 map.

\subsubsection{NDVI 2000 \& CLC 2012}

The south part of NDVI map 2000 for the Mitrovica has demonstrated the low values, it represents water bodies and barren area and rock surfaces as well settlements, which in general was corresponded to the CLC 2012 map. The central part of NDVI map 2000 has reported values close to zero which also matched with CLC 2012 map. The north part of NDVI map 2000 partly corresponded to the CLC 2012. In this region the NDVI map indicates water bodies, barren and rock surface which is contrast to the CLC 2012 map, which indicates agricultural areas and forests.
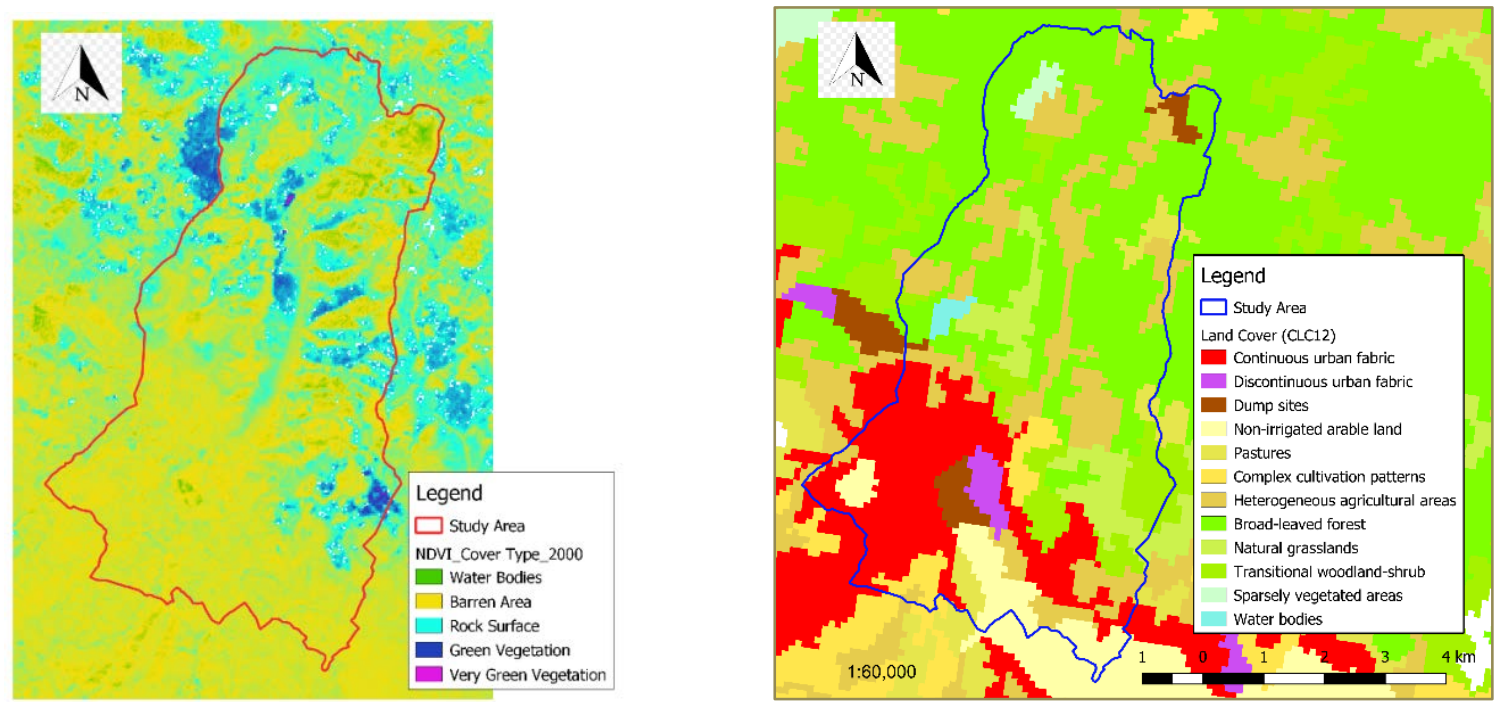

Figure 7. The NDVI cover types (2000) and Land cover (CLC 2012).

\subsubsection{NDVI 2010 \& CLC 2012}

The NDVI map 2010 was compared with CLC 2012 map as well. The study has shown that in the most of surfaces the NDVI map have not correspond to the CLC 2012 map. The NDVI map 2010 in the west part of Mitrovica indicates water bodies, barren area, rock surfaces, shrub and grasslands which is in the contrast to the CLC 2012 map which indicates urban surfaces and forests. In the specific part the NDVI map 2010 represents shrub whereas the CLC 2010 indicates dump 
sites which is contrast between NDVI map and CLC 2012. In other surfaces, mainly the NDVI map 2010 complies to the CLC 2012 map.
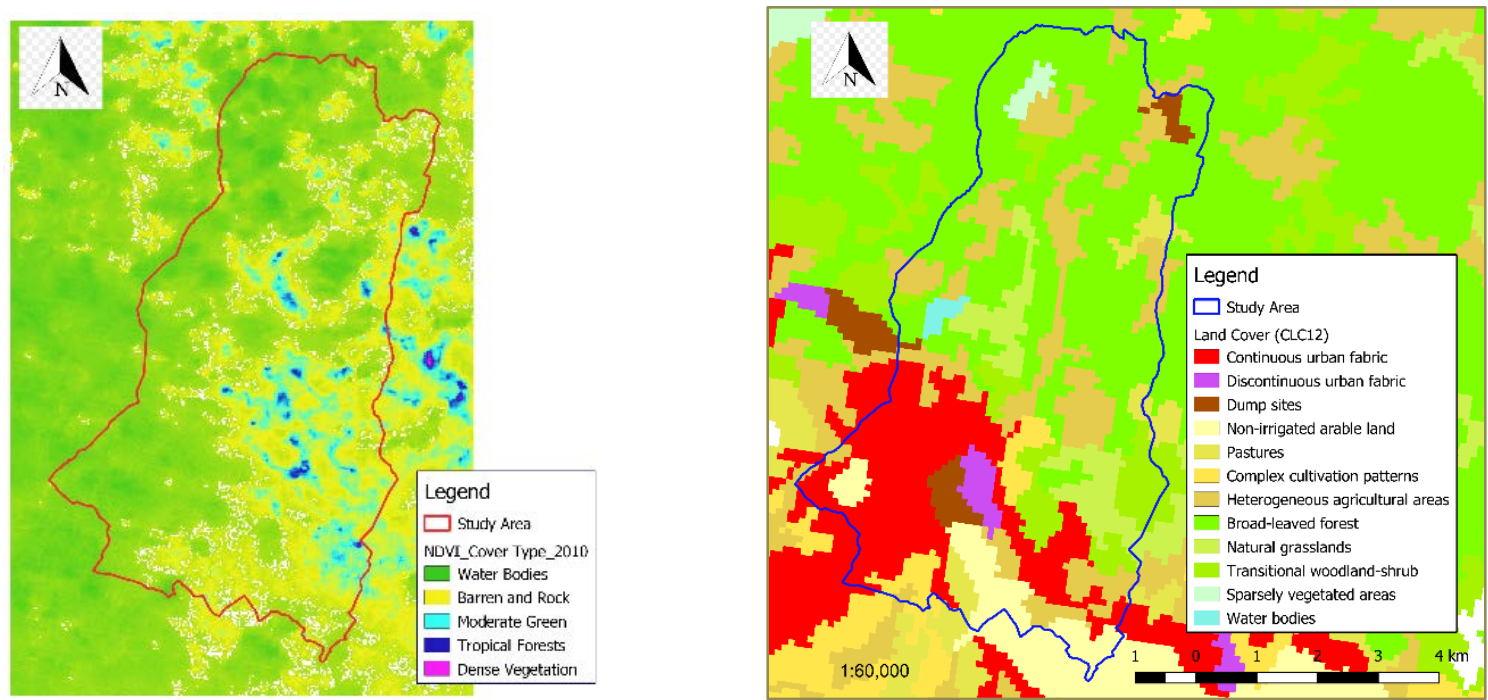

Figure 8. The NDVI cover types (2010) and Land cover (CLC 2012).

\subsubsection{NDVI 2018 \& CLC 2012}

The NDVI map 2018 has reported a high values representing moderate vegetation, very green vegetation tropical forests and dense vegetation which is in the most of cases was matched with CLC 2012 map and in some specific cases is in the contrast with CLC 2012 map. However, there are some area where the NDVI map 2018 has reports as very green vegetation whereas the CLC 2012 map has demonstrated that there are artificial surfaces or urban areas. As well as there is a situation in which the NDVI map 2018 indicates tropical forests (positive value close to zero), in the contrast with CLC 2012 map which indicates agricultural areas or pastures.
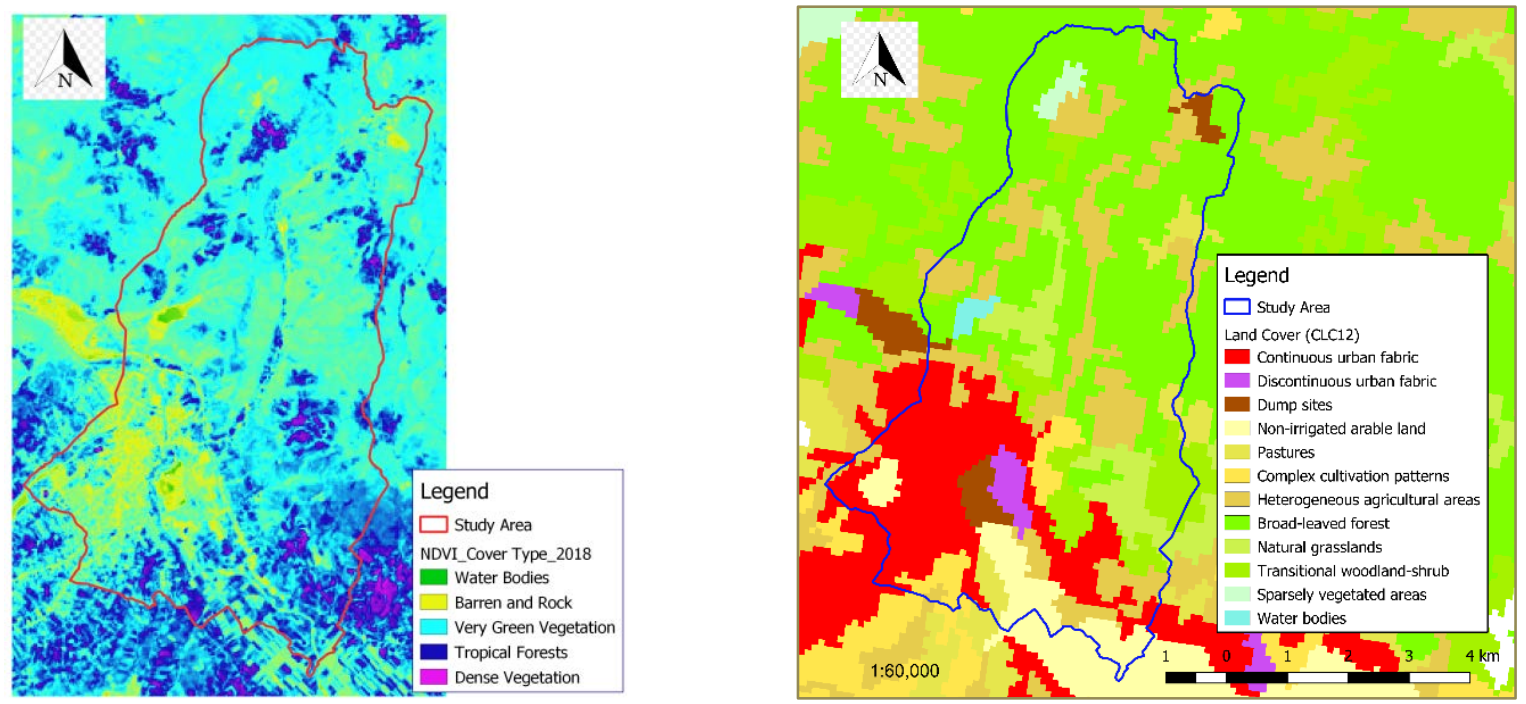

Figure 9. The NDVI cover types (2018) and Land cover (CLC 2012). 


\subsection{NDVI vs. DEM}

The elevations were obtained from DEM map, which was acqiured by ALOS 20m sptaial resolution. This is choosen as a appropriate method to evaluate the variation of NDVI time series map with topography. As well as, the elevation and slope information were helped to evaluate presence or absence of NDVI classes in specific elevation area. For example, water bodies or agricultural lands in tropical regions like Mitrovica are not expected to be located in higher elevations. These regions could be as dense vegetation or barren area. In the present study was choosen to evaluate the variation of NDVI time series within the study area, based on elevation and slope information. The mentioned criterion was used in entire area in Mitrovica. The analyse has shown a large change of elevations in the Mitrovica. The following table (Table 7) gives minimum, maximum and slope computed from DEM.

Table 7. Minimum and maximum elevation and slope in the study area.

\begin{tabular}{|ccccc|}
\hline \multirow{3}{*}{ The Study Area } & \multicolumn{3}{c}{ Elevation (m) } & \multicolumn{2}{c|}{ Slope $\left(^{\circ}\right)$} \\
\cline { 2 - 5 } Mitrovica & Min & Max & Min & Max \\
\cline { 2 - 5 } & 500 & 1220 & 0 & 50 \\
\hline
\end{tabular}

In the NDVI 2000 map compared with DEM, was demonstrated that NDVI values less than zero, in general were found in the regions with 500-750m elevation but there are in some regions with higer elevation than $750 \mathrm{~m}$ as well. Whereas the positive NDVI values were found in some areas in the regions with $850 \mathrm{~m}, 780 \mathrm{~m}$ and $1010 \mathrm{~m}$ elevation but in small quantities.
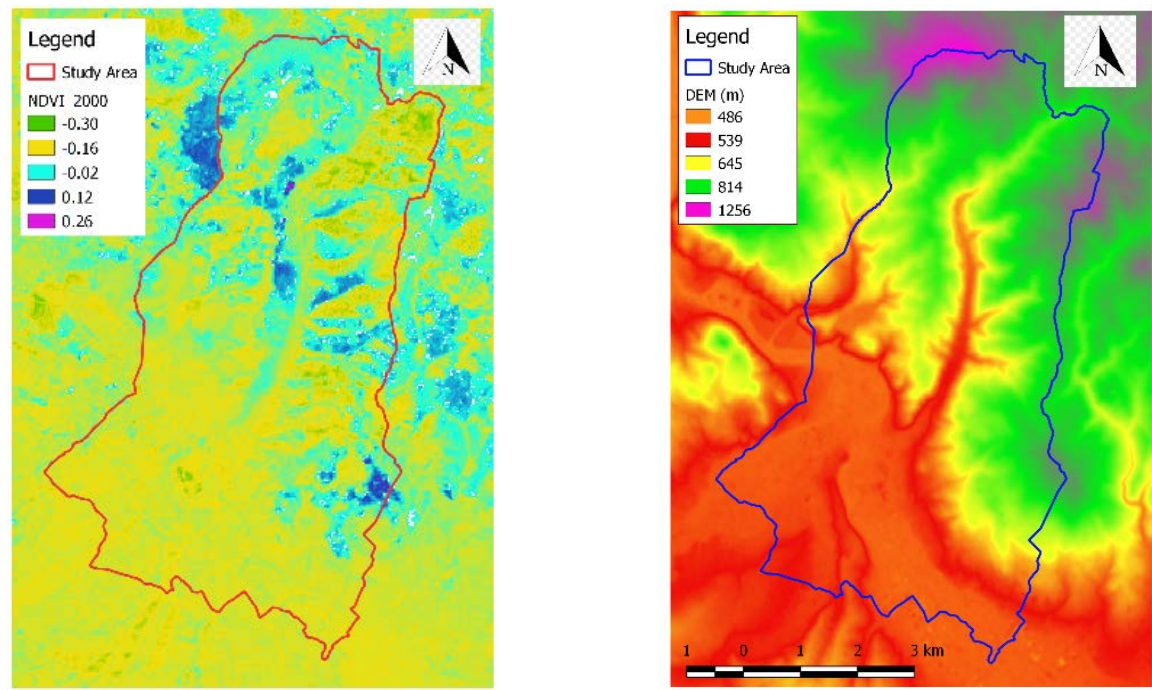

Figure 10. The NDVI values (2000) and Land cover (CLC 2012).

In the NDVI 2010 map, the negative NDVI values were located in different elevations, from $505 \mathrm{~m}-1230 \mathrm{~m}$. As well as the positive NDVI values were found in the regions of $520 \mathrm{~m}-950 \mathrm{~m}$ in consdierable quantities respectively. 

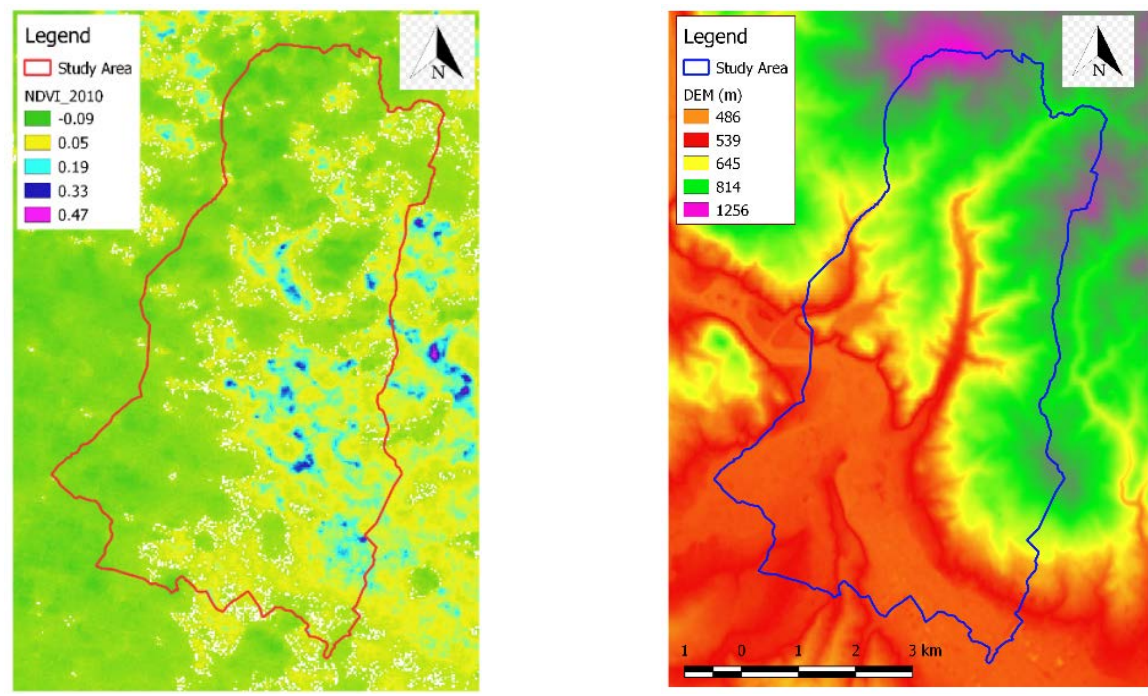

Figure 11. The NDVI values (2010) and Land cover (CLC 2012).

In similar way was estimated the NDVI 2018 map and the study has shown that the NDVI values less than zero known as water bodies were located in the region of $505 \mathrm{~m}$ and in the region of $580 \mathrm{~m}$ elevation but in very small quantities. Whereas the positive NDVI values representing moderate vegetation, very green vegetation and dense vegetation, were located in the regions of 506m $1220 \mathrm{~m}$ elevation, in very large quantities as well.
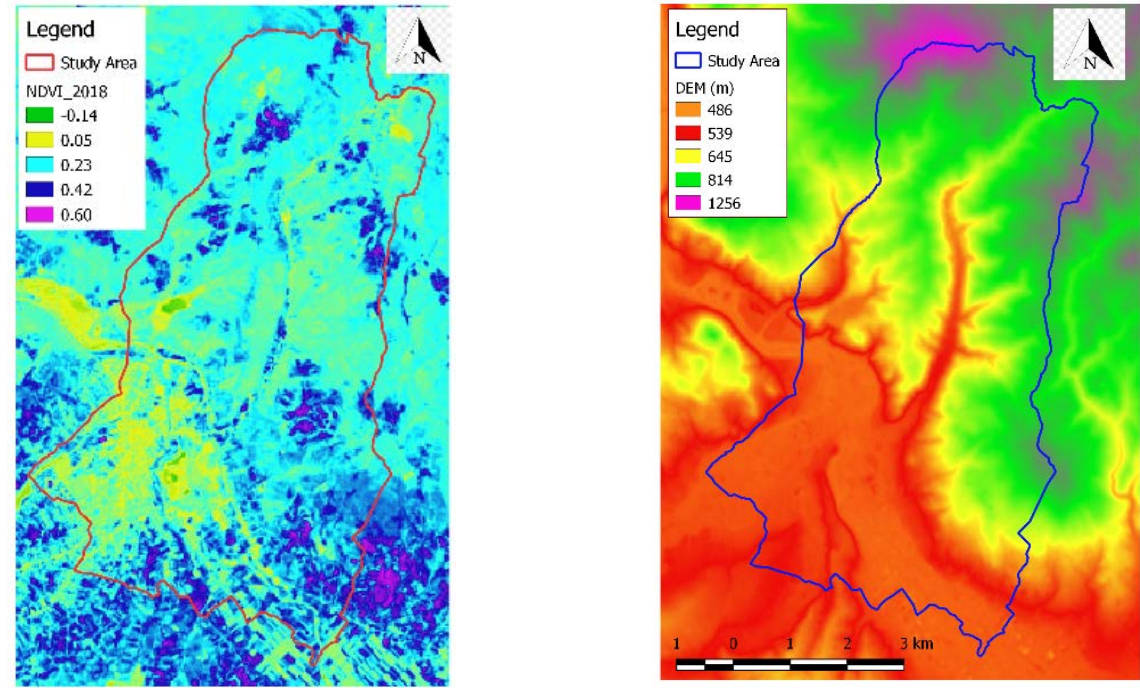

Figure 12. The NDVI values (2018) and Land cover (CLC 2012).

\section{CONLCUSIONS}

The performed study has confirmed the usage of NDVI technique for monitoring vegatation change. In the present study was demonstrated that the NDVI technique can be employed to monitor the vegetation change in particular and to monitor the environment in general. The various vegetation index maps from NDVI time series data were carefully analyzed. The NDVI values were a good indicator for vegetation cover.

At the local scale, the NDVI time series maps were correlated to vegetation cover categories compared with the Land Cover map (CLC 2012), although some uncertainties were observed. However, the NDVI time series maps can be useful for general vegetation monitoring and spatial 
planning as well. Based on the NDVI time series maps can be identified vegetation cover and land cover categories in the Mitrovica.

In general, the study has shown that vegetation in Mitrovica were changed over the years. The monitoring procces of vegetation in Mitrovica has shown that in 2000 there were a high level of drought. But in the last years the vegetation is being generated and is growing up as well. The NDVI map 2010 has demonstrated that vegetation is more healthy than in 2000 as well as the NDVI map 2018 has demostrated that vegetation is more healthy than in 2010. The dry surface is running decreased in Mitrovica. The main cause of the vegetation change in Mitrovica still remains industrial acitivity. Since 2000, when is stopped the industrial acitivity in this region the vegetation is improving and generating. Thus, mining tailings in Mitrovica should manage and monitor in order to have the minimum influence in environment in general and in vegetation in particular. Because the main source of vegetation drought remains mining tailings located in this region which cover an area of $0.6 \mathrm{~km}^{2}$.

From the NDVI time series indices can be predicted the Mitrovica cover type. The NDVI time series values have shown that Mitrovica land cover categories were such as barren, rock, water, shrubs, grasslands, dry bare soil, moderate vegetation, tropical and dense vegetation.

By applying the NDVI technique, the authors assesment have been that vegetation in Mitrovica is improved in the last years and it should be a good news for Mitrovica environment and its residents as well.

\section{Acknowledgements}

The present study is part of Edon Maliqi's Ph.D. thesis, which is supervises by Prof.Dr. Petar Penev in the University of Architecture, Civil Engineering and Geodesy; Department of Photogrametry and Cartography; Sofia, Bulgaria.

\section{References}

[1] Amiri, F., and Tayebeh, T. (2009). “Operational Monitoring of Vegetative Cover by Remote Sensing in Semi-arid Lands of Iran". Advanced.

[2] Arulbalaji, P. and Gurugnanam, B. (2014). "Evaluating the normalized difference vegetation index using landsat data by ENVI in salem district, Tamilnadu, India”. International Journal of Development research.

[3] Bannari, A., Morin, D., Bonn F. and Huete, A. R. (1995). “A review of vegetation indices”. Remote Sensing Reviews, 13(1), 95-120.

[4] Bannari, A., Morin, D., Bonn, F. And Huete, A. R., (1995). “A review of vegetation indices”. Remote Sens. Rev. 13, 95-120.

[5] Huete, A. R. and Jackson, R. D., (1988). "Soil and atmosphere influences on the spectra ofpartial canopies". Remote Sens. Environ. 25, 89-105.

[6] Jackson, R. D. and Huete, A. R., (1991). “Interpreting vegetation indices”. Prev. Vet. Med. 11,185-200.

[7] Reddy. A. and Reddy M., (2013). "NDVI based assessment of Land Use Land Cover dynamics in a rainfed watershed using Remote Sensing and GIS”. International Journal of Scientific \& Engineering Research, Volume 4, Issue 12.

[8] Rouse, J. W., Haas, R. H., Schell, J. A. and Deering, D. W., (1973). "Monitoring vegetation sys-tems in the great plains with ERTS”. In: Third ERTS Symposium, NASA SP-351 I, pp. 309-317.

[9] Slik, B., (2016). "Using vegetation indices from satellite images to estimate evapotranspiration and vegetation water use in north-central portugal”. Master Thesis. University of applied sciences Van Hall Larenstein (VHL). Netherland

[10] Thiam, A. \& Eastman, J. R. (2001). "Vegetation indices in IDRISI 3.2 release 2, guide to GIS and image processing”. Volume 2. Clark University.

[11] Weier J, Herring D. (2013). “Measuring Vegetation”. Office TEOEPS (ed.). 